\title{
The Study on Nonlinear Model of Pantograph-Catenary Coupling System for Straddle-Type Monorail
}

\author{
Zixue DU*, Zhen YANG**, Zhouzhou XU***, Junchao ZHOU****, Zhongwei HOU***** \\ *Institute of Urban Rail, Chongqing Jiaotong University, 400074 Chongqing, PR China, E-mail: aaadzx@163.com \\ **Institute of Urban Rail, Chongqing Jiaotong University, 400074 Chongqing, PR China, E-mail: yangz0000@163.com \\ ***Institute of Urban Rail, Chongqing Jiaotong University,400074 Chongqing, PR China, E-mail: 33243665@qq.com \\ ****Institute of Urban Rail, Chongqing Jiaotong University, 400074 Chongqing, PR China, E-mail: zhou1987g@163.com \\ *****Institute of Urban Rail, Chongqing Jiaotong University, 400074 Chongqing, PR China, E-mail: 13778257@qq.com \\ cross $^{\text {ref }}$ http://dx.doi.org/10.5755/j01.mech.26.3.24287
}

\section{Introduction}

Straddle-type monorail is a new type form of urban rail transit system which has some advantages such as: small turning radius, low manufacturing cost, strong climbing ability and ride comfort [1,2]. Because of the unique driving principle of straddle-type monorail vehicles, the structure of atraddle-type monorail bogie is also special. The running part of the bogie consists of four running wheels, four guiding wheels and two stabilizing wheels, all of which are rubber tires. While running wheels provide the longitudinal movement, guide wheels lead the monorail vehicle along the track. Moreover, stabilization wheels prevent excessive rolling motion of the monorail. The catenary of straddletype monorail is rigid catenary, positive and negative catenary are set on the left and right side of the track beam respectively. Because the rubber tires of running wheel, guide wheel and stabilizer wheel are flexible. Therefore, the bogie is sensitive to lateral external effects such as track alignment change, turnout joint transition and cross wind during operation, which will lead the lateral vibration of the bogie.

Because of the unique driving principle of straddle-type monorail, the interaction between side mounted pantograph and the side catenary is also special. Therefore, the interaction between side mounted pantograph of the monorail and the side catenary is one of the factors that limits the operating safety of monorail. The working environment of straddle-type monorail vehicle pantograph is different from that of metro and high-speed railway, so it is necessary to study the pantograph modeling of straddletype monorail.

Traditional dynamics research of pantograph system is mainly focused on railway [3-12]. In previous study, linear pantograph model is used to study pantographcatenary interactive. The liner model [13-15] simplifies the pantograph into several lumped mass objects using the principle of kinetic energy equivalence. But the lumped mass model can't reflect the higher frequency vibration of catenary.

Massat [16] establishes three-dimensional rigid body model of pantograph using MSC software. Rauter [17] establishes a multi-rigid-body dynamic model of pantograph, the number of objects and the position of articulation in the model are close to the real body. Ambrosio [18] established a rigid-flexible hybrid model of pantograph. There is no research on pantograph modeling of straddle-type monorail. Therefore, research the accurate pantograph model suit for straddle-type monorail has great significance to improve the operation safety of straddle-type monorail.

\section{Dynamic model and motion differential equation of pantograph}

\subsection{Two-dimensional model of pantograph}

Straddle-type monorail pantograph is mainly composed of a bottom plate, a lower frame, an upper frame, a connecting rod, a balance bar, a pantograph head seat, a pantograph spring, a pantograph head and a cylinder parts (positive pantograph only) and so on. The pantograph is reduced to the model shown in Fig. 1 a. $A$ is the hinge point between the lower frame and the bottom plate, $B$ is the hinge point between the connecting rod and the bottom plate, $C$ is the hinge point between the lower frame and the upper frame, $D$ is the hinge point between connecting rod and the lower frame, $E$ is the hinge point between balance bar and the connecting rod, $F$ is the hinge point between balance bar and the pantograph seat, $G$ is the hinge point upper frame bar and the bow head, $K$ and $P$ are the installation position of pantograph spring. $Q_{1}, Q_{2}, Q_{3}, Q_{4}, Q_{5}$ are the gravity center of lower frame, upper frame, connecting rod, balance bar, bow head seat respectively. $\alpha, \beta, \gamma, \delta$ are the angles between $A C, B D, C D, A B$ and $X$ axis respectively, $\varepsilon$ is the angle between $C D$ and $C G, \theta$ is the angle between $F G$ and $X$ axis. $F_{\mathrm{c}}$ is the contact force between pantograph and catenary. Since the lower frame is the active part, $A$ is selected as the origin point of coordinate system, the direction of the monorail running is defined as the positive direction of the $X$ axis, the yaw direction of the vehicle is defined as the $Y$ axis, the vertical upward direction is the positive direction of the $Z$ axis.

\subsection{Differential equation of pantograph head}

The motion differential equation of pantograph head component is established on the basis of Newton's second law [2-5].

$$
\begin{aligned}
& M_{H} \ddot{z}_{H}+K_{H}\left(y_{H}-y_{G}-\Delta l_{0}\right)+ \\
& +C_{H}\left(\dot{y}_{H}-\dot{y}_{G}\right)_{H}=F_{C}-M_{H} \zeta_{(t)},
\end{aligned}
$$

where: $M_{H}$ is the mass of pantograph head; $\Delta \ddot{z}_{\mathrm{H}}$ is the vertical displacement of pantograph head component; $F_{c}$ is the contact force between the pantograph head and catenary; $K_{H}$ 
and $C_{H}$ are the stiffness and damping of bow head elastic elements, $\Delta l_{0}$ is the natural length of the elastic element.

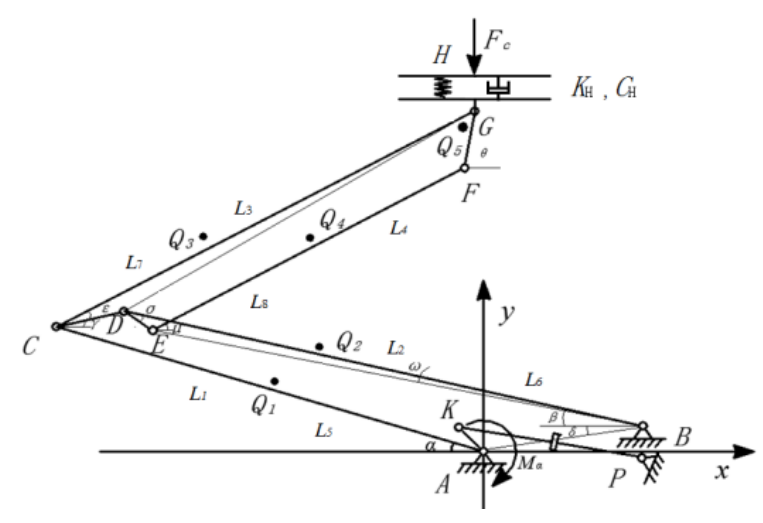

a

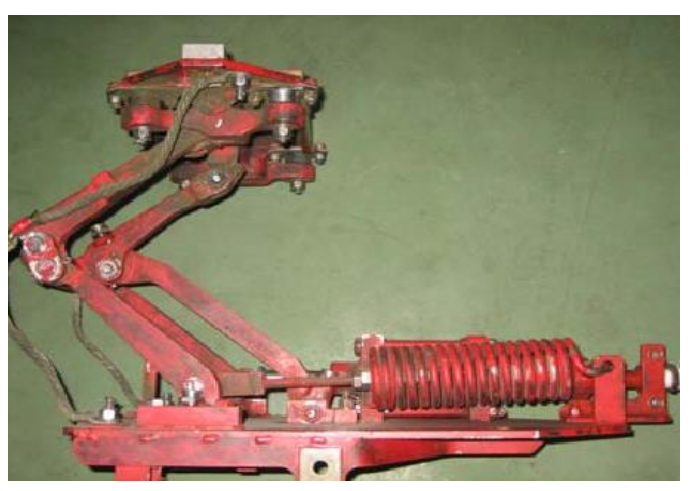

b

Fig. 1 Model of pantograph: a) multi rigid body dynamic model; b) pantograph of monorail

\subsection{Differential equation of pantograph frame}

Since the frame portion of the pantograph has only one degree of freedom. The angle $\alpha$ can be regarded as the independent variable. According to Lagrange equation:

$$
\frac{d}{d t} \frac{\partial L}{\partial \dot{\alpha}}-\frac{\partial L}{\partial \alpha}=Q_{\alpha},
$$

where: $Q_{\alpha}$ is generalized force; $L=T-V . T$ is the total kinetic energy of the frame system; $V$ is the total potential energy of a frame system, $V=0$.

$$
T=T_{\text {Lower }}+T_{L G}+T_{U p p e r}+T_{U G}+T_{H},
$$

where: $T_{\text {Lower }}, T_{L G}, T_{U p p e r}, T_{U G}$ and $T_{H}$ are the kinetic energy of the lower frame, the connecting rod, the upper frame, the balance bar and the pantograph head seat respectively, which be found in reference [19].

Because the pantograph of monorail vehicle is enveloped by the whole car body, the influence of aerodynamic force on Pantograph can be ignored. Considering the damping of the hinge, the dry friction moment, the damping force of the pantograph spring, the lifting bow moment and the force between the bow head and the frame, the virtual work done on the frame is as follows:

$$
\begin{aligned}
& W=Q_{\alpha} \delta \alpha= \\
& =\left\{M_{\alpha}-F_{h}\left[l_{A C} \cos \alpha+k_{3} l_{C G} \cos (\gamma+\varepsilon)\right]-\right. \\
& -c \frac{d l_{K P}}{d \alpha} l_{K P} \sin \angle A K P \cdot \dot{\alpha}-\left[U_{A}+k_{2}^{2} U_{B}+\right. \\
& +\left(1+k_{3}\right)^{2} U_{C}+\left(k_{2}+k_{3}\right)^{2} U_{D}+\left(k_{2}+k_{4}\right)^{2} . \\
& \left.\cdot U_{E}++\left(k_{4}+k_{5}\right)^{2} U_{F}+\left(k_{3}+k_{5}\right)^{2} U_{G}\right] \cdot \dot{\alpha}- \\
& -\left[B_{A}+\left|k_{2}\right| B_{B}+\left|1+k_{3}\right| B_{C}+\left|k_{2}+k_{3}\right| B_{D}+\right. \\
& \left.+\left|k_{2}+k_{4}\right| B_{E}+\left|k_{4}+k_{5}\right| B_{F}+\left|k_{3}+k_{5}\right| B_{G}\right] . \\
& \cdot \operatorname{sgn}(\dot{\alpha})\} \cdot \delta \alpha .
\end{aligned}
$$

In summary, the motion differential equation for the whole pantograph frame of straddle-type monorail can be obtained:

$$
\begin{aligned}
& f_{1}(\alpha) \ddot{\alpha}+f_{2}(\alpha) \dot{\alpha}^{2}+f_{3}(\alpha) \dot{\alpha}+ \\
& +f_{4}(\alpha) \operatorname{sgn}(\dot{\alpha})+f_{5}(\alpha, \dot{\alpha})=0
\end{aligned}
$$

The relevant variables in the formula can be found in the reference [19].

The pantograph can be simplified to a linear model with two degrees of freedom by expanding the differential equation of the pantograph frame at the equilibrium position and ignoring the influence of the higher order terms (Fig. 2).

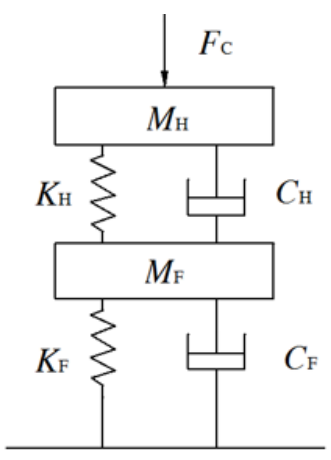

Fig. 2 Linear model of pantograph

$$
\begin{aligned}
& M_{F} \Delta \ddot{z}_{E}+\left(C_{H}+C_{F}\right) \Delta \dot{z}_{F}- \\
& -C_{H} Z_{H}+B_{F} \operatorname{sign}\left(\frac{\Delta Z_{E}}{k_{3}}\right) k_{h}+ \\
& +\left(K_{H}+K_{F}\right) \Delta Z_{E}-K_{H} \Delta Z_{H}=0,
\end{aligned}
$$

where: $M_{F}=\frac{f_{1}(\alpha)}{k_{3}^{2}}$;

$$
\begin{aligned}
& K_{F}=-\frac{1}{k_{6}^{2}}\left[\frac{d M_{\alpha}}{d \alpha}-\left(F_{c 0}+M_{H} g\right)\left(-L_{1} \sin \alpha+\frac{d k_{3}}{d \alpha} L_{3} \cos \gamma-\right.\right. \\
& \left.-k_{2}^{2} L_{3} \sin \gamma\right)+M_{1} g L_{3} \sin \alpha+\frac{d k_{2}}{d \alpha} M_{2} g L_{4} \cos \beta+ \\
& +k_{2}^{2} M_{2} g L_{6} \sin \beta+M_{3} g L_{1} \sin \alpha-\frac{d k_{3}}{d \alpha} M_{3} g L_{7} \cos \gamma+ \\
& +k_{3}^{2} M_{3} g L_{7} \sin \gamma+M_{4} g L_{1} \sin \alpha- \\
& \left.-\frac{d k_{4}}{d \alpha} M_{4} g L_{8} \cos \mu+k_{4}^{2} M_{4} g L_{8} \sin \mu\right]
\end{aligned}
$$


$C_{\mathrm{F}}=\frac{f_{3}(\alpha)}{k_{6}^{2}} ; k_{1}=L_{1} \cos (a)+k_{3} L_{3} \cos (\gamma)$.

$M_{a}$ is the torque of pantograph raising, which can be found in reference [19].

\subsection{Differential equation of pantograph frame}

According to the displaying center difference formula, the displacement of pantograph head:

$$
\left\{\begin{array}{l}
Z_{H(n)}=Z_{H(n-1)}+\frac{1}{2}\left(Z_{H(n-1)}+Z_{H(n)}\right) \Delta t \\
Z_{H(n)}=Z_{H(n-1)}+Z_{H(n-1)} \Delta t+\frac{1}{2} Z_{H(n-1)} \Delta t^{2}
\end{array},\right.
$$

where: $Z_{G}$ is the displacement of point $G$ at the top of frame. According to the geometric relationship, $Z_{G}$ can be represented by angle $\alpha$ and $\dot{Z}_{G}$ is derived by $Z_{G}$.

$$
\left\{\begin{array}{l}
Z_{G(N)}=L_{1} \sin a_{n}+L_{4} \sin \gamma_{n}- \\
-L_{1} \sin a_{0}-L_{4} \sin \gamma_{0} \\
\dot{Z}_{G(N)}=\left(L_{1} \cos a_{n}+L_{4} \cos \gamma_{n} K_{3}\right) \dot{a}_{n}
\end{array},\right.
$$

where: $\alpha_{0}$ is the angle between $L_{1}$ and the pantograph support for the initial position. $\gamma_{0}$ is the angle between $L_{3}$ and the pantograph support for the initial position.

According to the displaying center difference formula, the pantograph lift angle is:

$$
\left\{\begin{array}{l}
a_{n}=a_{n-1}+\dot{a}_{n-1}+\frac{1}{2} \ddot{a}_{n-1} \Delta t^{2} \\
\dot{a}_{n}=\dot{a}_{n-1}+\frac{1}{2}\left(\ddot{a}_{n}+\ddot{a}_{n-1}\right) \Delta t
\end{array} .\right.
$$

According to formulas (1) and (7)-(9), the pantograph head acceleration $Z_{H(n)}$ at $n$ time can be obtained.

$$
\begin{aligned}
& Z_{H(n)}=\left\{K_{H}\left[Z_{G(n)}-Z_{H(n)}\right]+C_{H}\left[Z_{G(n)}-Z_{H(n-1)}-\right.\right. \\
& \left.\left.-\frac{1}{2} \Delta t Z_{H(n-1)}\right]-F_{C}-M_{H}\right\} /\left(M_{H}+\frac{1}{2} C_{H} \Delta t\right) .
\end{aligned}
$$

According to formulas (1) and (7)-(10), the force $F_{H}$ between bow head and frame can be expressed by $\ddot{a}_{n}$. By introducing $F_{H}$ into Eq. (6), we can get a one-dimensional equation about $\ddot{a}_{n}$. This is the differential equation of whole pantograph.

$$
A \ddot{a}_{n}^{2}+B \ddot{a}+C=0,
$$

where: $A=f_{2}\left(\alpha_{n-1}\right) \Delta t^{2} / 4$;

$$
\begin{aligned}
& B=\left[f_{1}\left(\alpha_{n-1}\right)+f_{2}\left(\alpha_{n-1}\right)\left(\dot{\alpha}_{n-1} \Delta t+\ddot{\alpha}_{n-1} \Delta t^{2}\right)+f_{3}\left(\alpha_{n-1}\right) \Delta t / 2+\right. \\
& \left.+M_{H} C_{H} \Delta t\left(L_{1} \cos \alpha_{n}+k_{3} L_{3} \cos \gamma_{n}\right)^{2}\right] /\left(2 M_{H}+C_{H} \Delta t\right)
\end{aligned}
$$

$$
\begin{aligned}
& C=f_{2}\left(\alpha_{n-1}\right)\left(\dot{\alpha}_{n-1}+\ddot{\alpha}_{n-1} \Delta t^{2} / 2\right)+f_{3}\left(\alpha_{n-1}\right)\left(\dot{\alpha}_{n-1}+\ddot{\alpha}_{n-1} \Delta t / 2\right)+ \\
& +m_{1} g L_{5} \cos \alpha_{n}+k_{2} m_{2} g L_{6} \cos \beta_{n}+m_{3} g L_{7} \cos \alpha_{n}+ \\
& +k_{3} m_{3} g L_{7} \cos \gamma_{n}+m_{4} g L_{4} \cos \mu_{n}+k_{4} m_{4} g L_{8} \cos \mu_{n}+ \\
& +\left(L_{1} \cos \alpha_{n}+k_{2} L_{3} \cos \gamma_{n}\right) \cdot\left\{M_{H} g+F_{C(n)}+\left\{-M_{H} g-F_{C(n)}+\right.\right. \\
& +K_{H}\left(L_{1} \sin \alpha_{n}+L_{3} \sin \gamma_{n}-L_{1} \sin \alpha_{0}-L_{3} \sin \gamma_{0}-Z_{H(n)}\right)+ \\
& +C_{H}\left[\left(L_{1} \cos \alpha_{n}+k_{2} L_{3} \cos \gamma_{n}-k_{2} L_{3} \cos \gamma_{n}-\right.\right. \\
& \left.-\left(\dot{\alpha}_{n-1}+\ddot{\alpha}_{n-1} \Delta t / 2\right)-\left(Z_{H(n-1)}+Z_{H(n-1)} \Delta t / 2\right]\right\} / \\
& /\left(2 M_{\mathrm{H}}+C_{H} \Delta t\right) .
\end{aligned}
$$

\subsection{Differential equation of catenary}

The catenary and aluminum profile base are regarded as Euler beam; electric insulator is regarded as lumped mass spring model. The stiffness within the span of the catenary is obtained by using the finite element method. The stiffness of the catenary in one span is obtained by using the finite element method. In order to simplify the calculation, the continuous equivalent stiffness of the catenary is used to replace by the stiffness $K_{(t)}$ :

$$
K_{(t)}=K_{0}\left[1+\lambda \frac{2 \pi}{L} V_{t}\right],
$$

where: $K_{0}$ is the average stiffness; $\lambda$ is nonuniformity coefficient of the stiffness; $L$ is the span of the catenary; $V$ is the speed of the monorail, $t$ is time.

$$
\left\{\begin{array}{l}
K_{0}=\frac{K_{\max }+K_{\min }}{2} \\
\lambda=\frac{K_{\max }-K_{\min }}{K_{\max }+K_{\min }}
\end{array},\right.
$$

where: $K_{\max }, K_{\min }$ are the maximum and minimum stiffness of the catenary in one span.

\subsection{Dynamic model of pantograph-catenary system}

The contact force between pantograph and catenary is provided by the pantograph spring. In this paper, penalty function is used to simulate the coupling between pantograph and catenary. When no offline occurs, the contact force is the product of catenary stiffness and pantograph-head displacement. combined the Differential equation of pantograph and Differential equation of catenary, the lateral coupling dynamic model of pantograph and catenary is obtained.

$$
M \ddot{a}(t)+C \dot{a}(t)+K a(t)=Q(t) .
$$

In the formula, $\ddot{a}(t)$ and $\dot{a}(t)$ are acceleration vectors and velocity vectors of system nodes respectively, $M$ is the mass matrix of the system; $C$ is the damping matrix of the system; $K$ is the stiffness matrix of the system; $Q(t)$ is the load vectors of the system.

\subsection{Lateral vibration model of bogie}

When the straddle monorail is running on the track, the excitation of the finger plate on the side of the track will 
be caused the lateral vibration of the bogie, which will affect the quality of power collection. The lateral vibration model of the monorail can be seen in Fig.3.

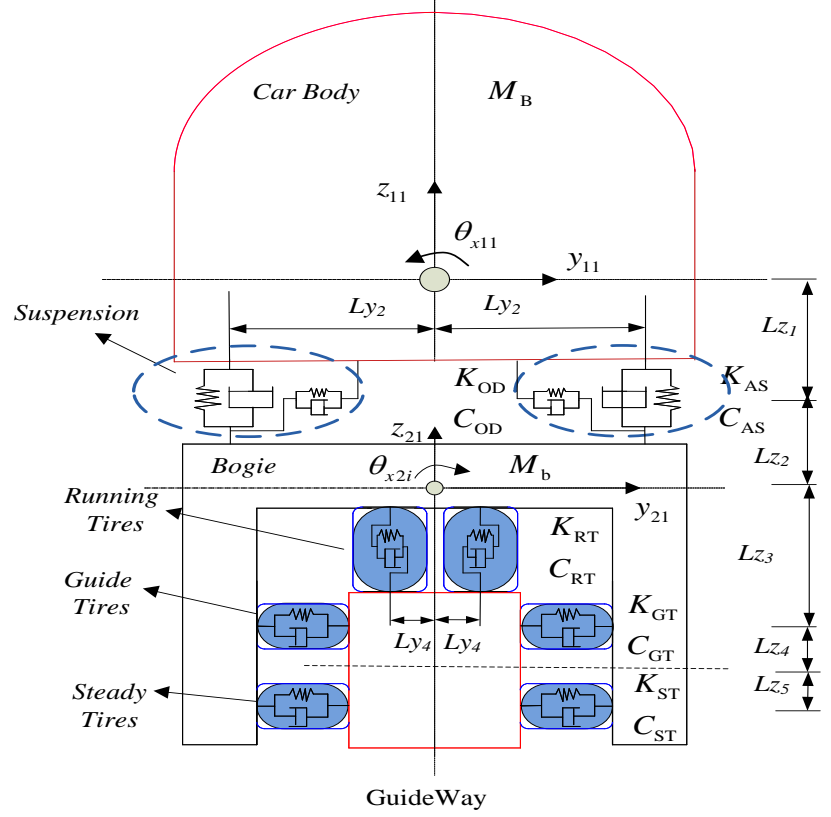

Fig. 3 Lateral vibration model of the monorail

$$
M_{b} \ddot{\mathrm{Z}}_{b}(t)=K_{b} \mathrm{Z}_{b}(t)+\mathrm{C}_{b} \dot{\mathrm{Z}}_{b}(t)
$$

where: $M_{b}$ is the mass of bogie; $Z_{b}(t)$ is the installation tolerances of lateral finger plate; $K_{b}$ is the equivalent lateral stiffness of Bogie, $C_{b}$ is the equivalent lateral damping of Bogie.

$$
K_{b}=K_{A S}+K_{O D}+4 K_{R T}+2 K_{G T}+K_{S T}
$$

where: $K_{A S}$ is the lateral stiffness of air spring; $K_{O D}$ is the lateral stiffness of oil-pressure damper; $K_{R T}$ is the lateral stiffness of running tire; $K_{G T}$ is the radial stiffness of guide tire; $K_{S T}$ is the radial stiffness of steady tire.

$$
C_{b}=C_{A S}+C_{O D}+4 C K_{R W}+2 C_{G W}+C_{S W},
$$

where: $C_{A S}$ is the lateral damping of air spring; $C_{O D}$ is the lateral damping of oil-pressure damper; $C_{R T}$ is the lateral damping of running tire; $C_{G T}$ is the radial damping of guide tire; $C_{S T}$ is the radial damping of steady tire.

Therefore, the lateral vibration acceleration of the monorail is as follow:

$$
\begin{aligned}
& \zeta_{(t)}=\ddot{\mathrm{Z}}_{b}(t)=\left\{\left[K_{A S}+K_{O D}+4 K_{R T}+\right.\right. \\
& \left.+2 K_{G T}+K_{S T}\right] \mathrm{Z}_{b}(t)+\left[C_{A S}+C_{O D}+\right. \\
& \left.\left.+4 C K_{R T}+2 C K_{G T}+C_{S T}\right] \dot{\mathrm{Z}}_{b}(t)\right\} / M_{b} .
\end{aligned}
$$

\section{Comparison of dynamic characteristics between nonlinear model and lumped mass model}

\subsection{Analysis of the contact force}

The maximum design speed of straddle monorail vehicle is $80 \mathrm{~km} / \mathrm{h}$. In order to evaluate the applicability of the two models, this paper analyzed the contact force response of two model with four different speeds of 20, 40, 60 and 80 $\mathrm{km} / \mathrm{h}$ respectively.
The track of straddle-type monorail is PC beam which is $22 \mathrm{~m}$ long each beam and set finger plate at the joint of two beam. The lateral installation tolerances of finger plate are $3 \mathrm{~mm}$. Therefore, when the vehicle passes through joint of two beam, the lateral vibration of the bogie will affect the contact force between pantograph and catenary. As can be seen from Figs. 4 and 5, two kinds of pantograph-catenary coupling models do not appear offline at all four speeds. At the speed of 20 and $40 \mathrm{~km} / \mathrm{h}$, the contact forces of the two models have periodic fluctuations and the fluctuation period is $22 \mathrm{~m}$, which reflects the transverse excitation of the finger plate. As can be seen from Figs. 6 and 7 , when the speed exceeds $40 \mathrm{~km} / \mathrm{h}$, only the nonlinear model can still reflect the lateral excitation of finger plate.

In order to more intuitively reflect the change of contact force between the two models with train running mileage, Fig. 8 shows the power collection quality evaluation index curve of the two models.

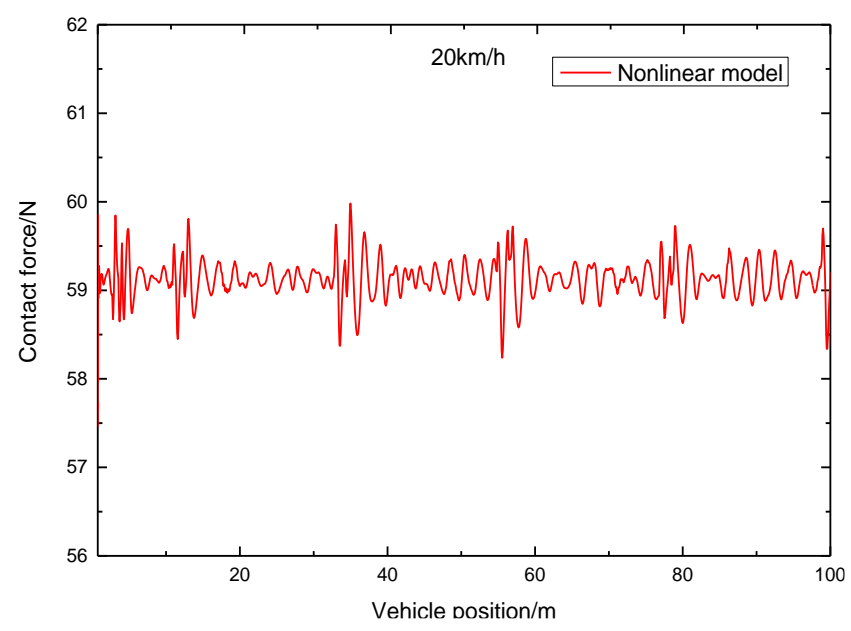

a

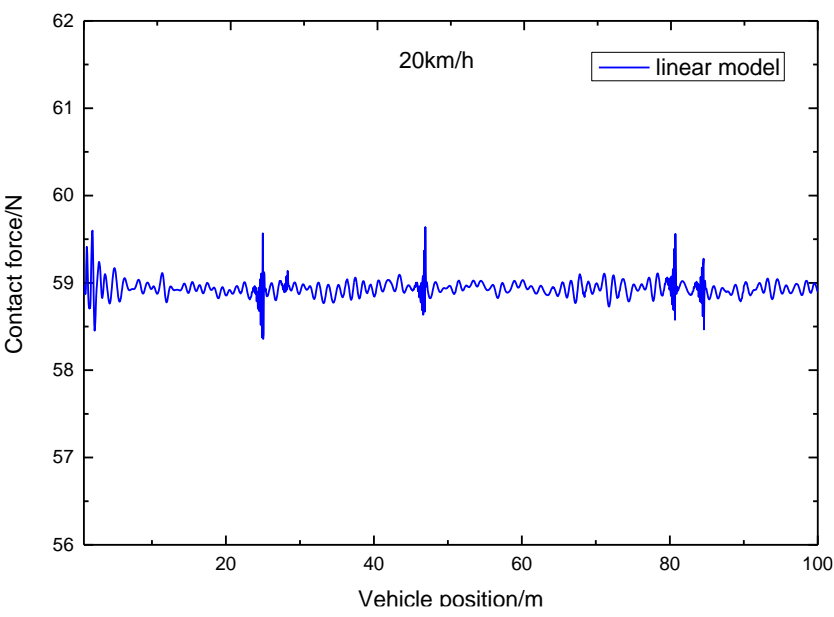

$\mathrm{b}$

Fig. 4 Contact force at the speed of $20 \mathrm{~km} / \mathrm{h}$ : a) nonlinear model; b) linear model

The statistical results show that the average contact force of the non-linear model reaches its maximum at $40 \mathrm{~km} / \mathrm{h}$, and decreases slightly with the increase of vehicle speed. The average contact force of linear model is almost not change at different velocities. At $40 \mathrm{~km} / \mathrm{h}$, the average contact force of the non-linear model is larger than that of the non-linear model, and at other velocities, the average contact force of the non-linear model is slightly smaller than that of the non-linear model. 


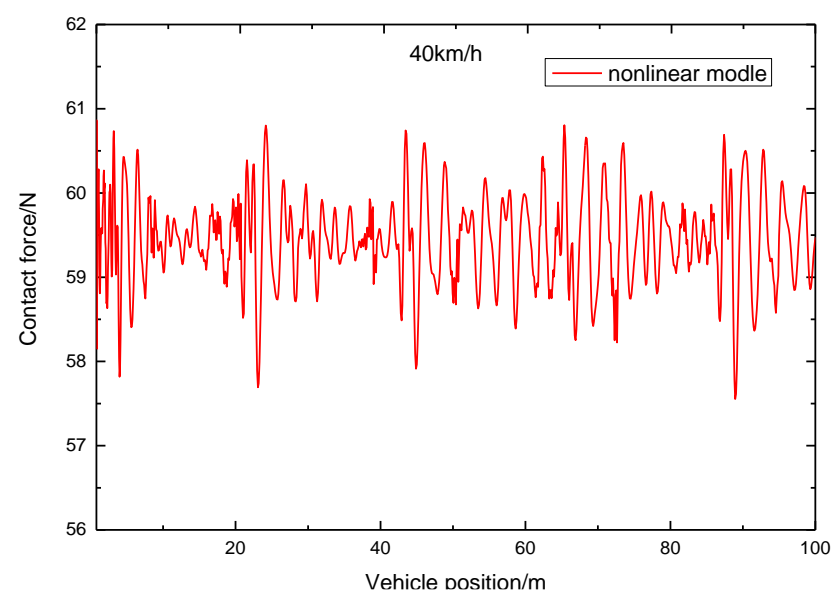

a

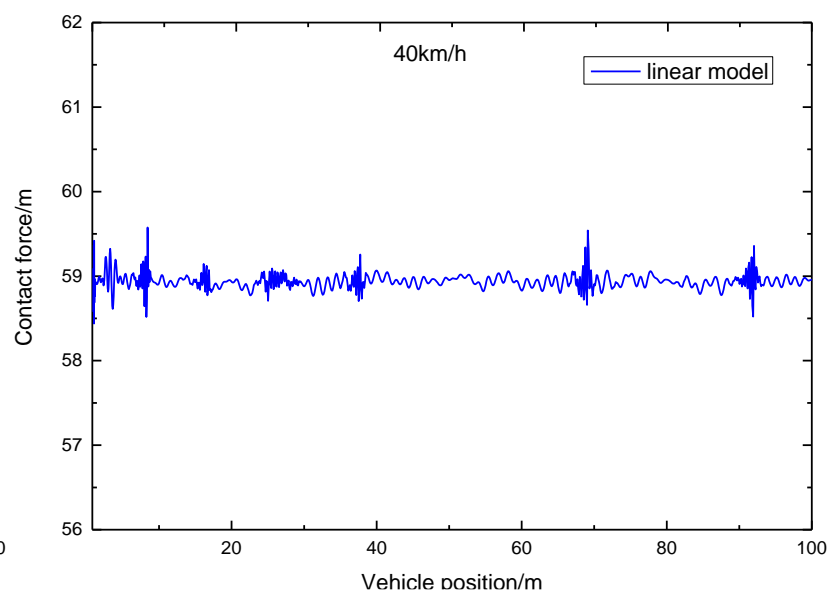

$\mathrm{b}$

Fig. 5 Contact force at the speed of $40 \mathrm{~km} / \mathrm{h}$ : a) nonlinear model; b) linear model

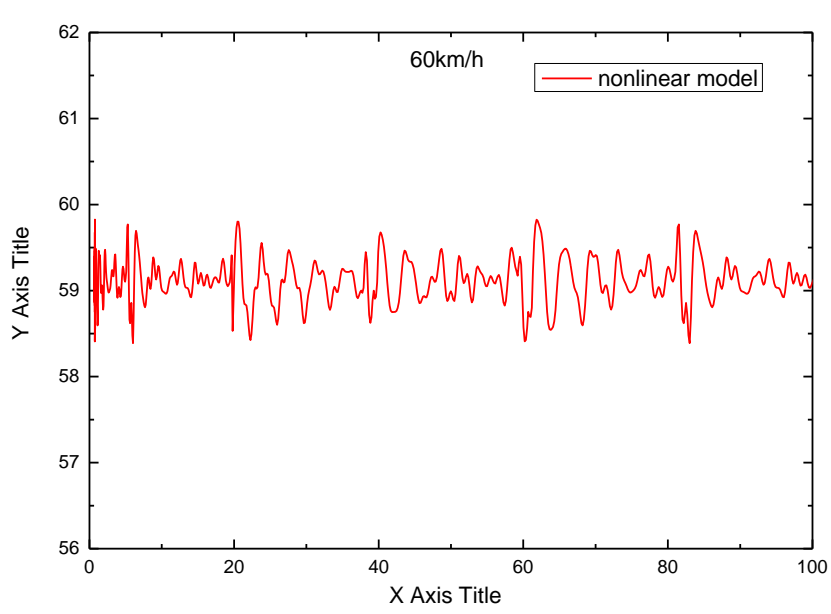

a

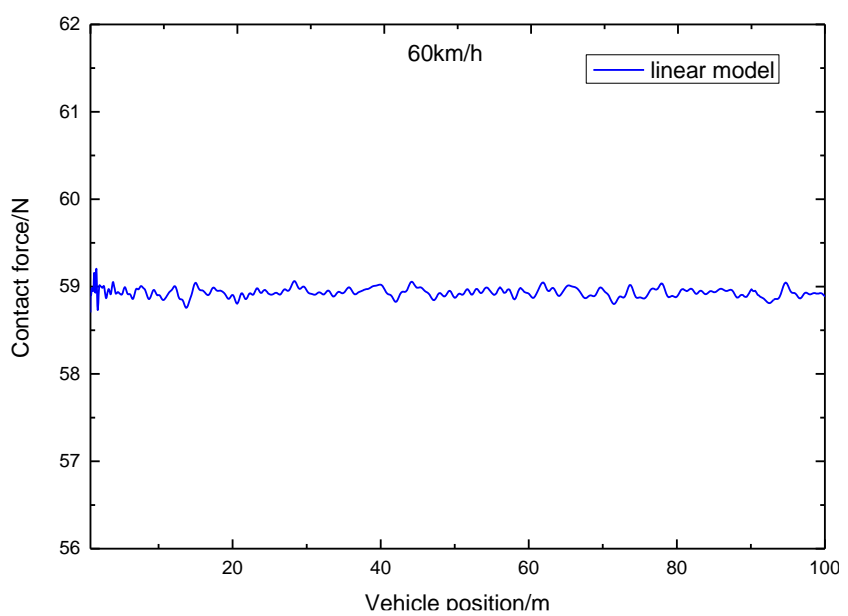

b

Fig. 6 Contact force at the speed of $60 \mathrm{~km} / \mathrm{h}$ : a) nonlinear model; b) linear model

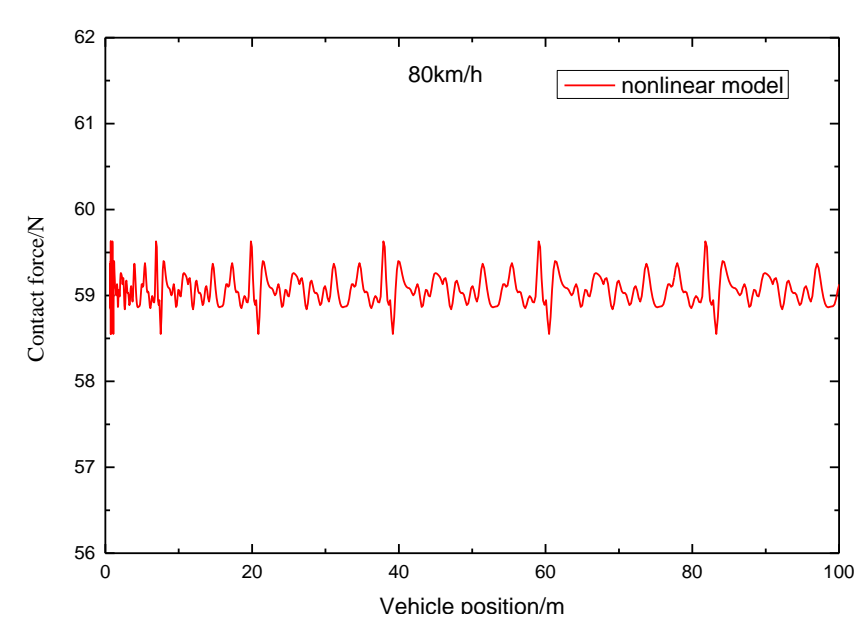

a

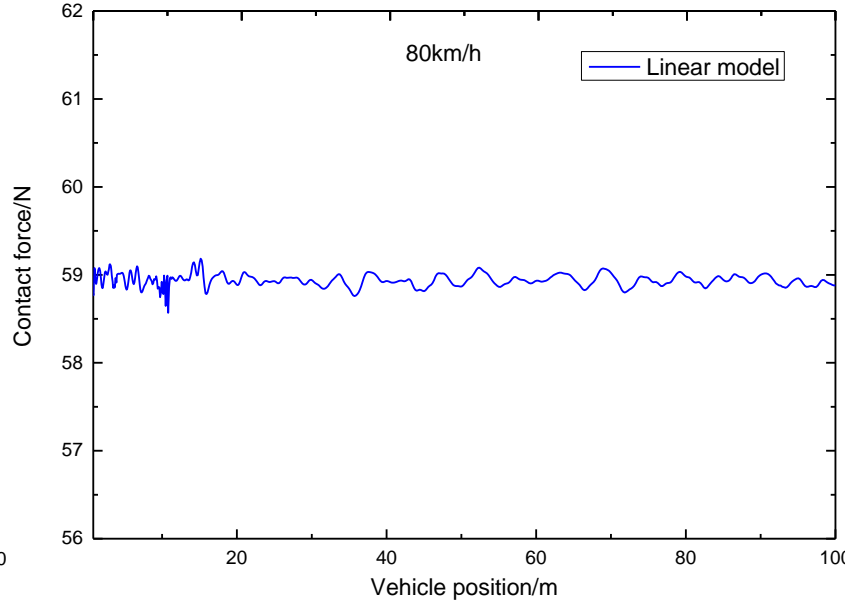

$\mathrm{b}$

Fig. 7 Contact force at the speed of $80 \mathrm{~km} / \mathrm{h}$ : a) nonlinear model; b) linear model

But for the standard deviation of contact force, the non-linear model reaches its maximum at $40 \mathrm{~km} / \mathrm{h}$, and then decreases with the increase of vehicle speed, the linear model decreases with the increase of vehicle speed. The standard deviation of contact force of non-linear model is larger than that of linear model at all the speed.

The Maximum contact force of the non-linear model is larger than that of the linear model, the Minimum contact force of the non-linear model is smaller than that of the linear model, so standard deviation of contact force of non-linear model is larger than that of linear model at all the speed. This is because the non-linear model is more sensitive to the lateral excitation than the linear model. 


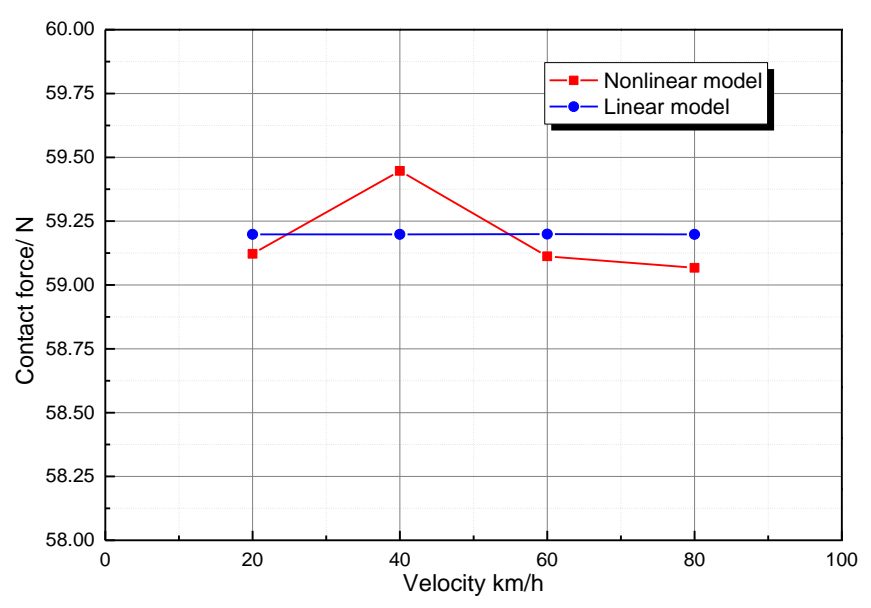

$\mathrm{a}$

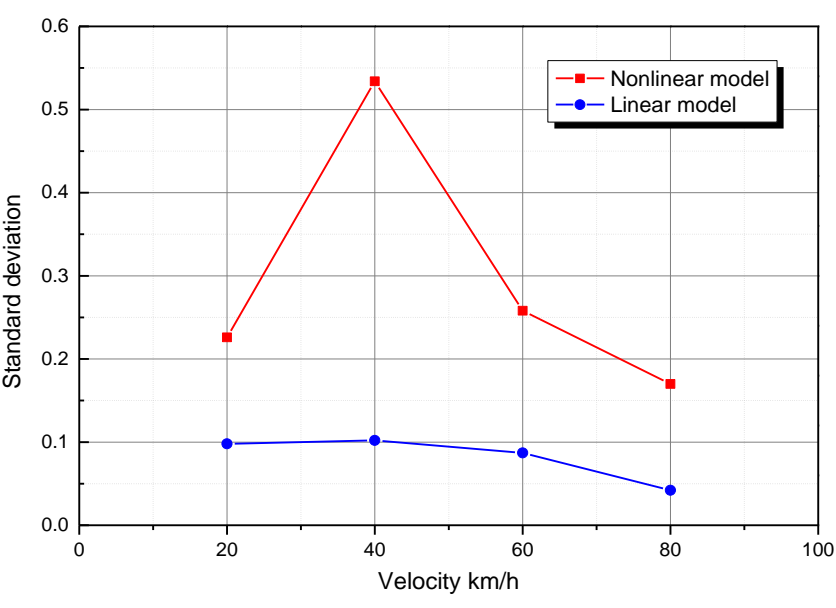

$\mathrm{b}$

Fig. 8 Comparison of two models: a) mean value of contact force; b) standard deviation of contact force

Table 1

The statistics of the power collection quality indexes of the pantograph-catenary system

\begin{tabular}{|c|c|c|c|c|c|c|}
\hline Velocity, $\mathrm{km} / \mathrm{h}$ & Model & Mean Value, $\mathrm{N}$ & Standard deviation, N & Maximum value, $\mathrm{N}$ & Minimum value, $\mathrm{N}$ & Offline Rate, $\%$ \\
\hline \multirow{2}{*}{20} & Nonlinear & 59.122 & 0.226 & 60.024 & 58.048 & 0 \\
\cline { 2 - 7 } & Linear & 59.198 & 0.098 & 59.757 & 58.506 & 0 \\
\hline \multirow{2}{*}{40} & Nonlinear & 59.447 & 0.534 & 62.186 & 57.553 & 0 \\
\cline { 2 - 7 } & Linear & 59.198 & 0.102 & 59.676 & 55.602 & 0 \\
\hline \multirow{2}{*}{60} & Nonlinear & 59.112 & 0.257 & 59.825 & 58.299 & 0 \\
\cline { 2 - 7 } & Linear & 59.199 & 0.087 & 59.686 & 58.757 & 0 \\
\hline \multirow{2}{*}{80} & Nonlinear & 59.068 & 0.170 & 59.629 & 59.550 & 0 \\
\cline { 2 - 7 } & Linear & 59.198 & 0.042 & 59.097 & 0 \\
\hline
\end{tabular}

\subsection{Frequency response analysis of contact force}

The spectrum analysis results of pantograph-catenary system are shown in Figs. 9-12. The spectrograms of the two models have three obvious peaks at the vehicle running speed of $20 \mathrm{~km} / \mathrm{h}$, the frequency of the non-linear model is $0.48,6.49$ and $21.13 \mathrm{~Hz}$, the frequency of the non-linear model is $0.48,6.49$ and $21.13 \mathrm{~Hz}$. The spectrograms of the two models have four obvious peaks at the vehicle running speed of $40 \mathrm{~km} / \mathrm{h}$, the frequency of the non-linear model is $0.48,8.00,13.11$ and $21.55 \mathrm{~Hz}$, the frequency of the nonlinear model is $0.50,7.99,14.85$ and $22.11 \mathrm{~Hz}$. The spectrograms of the two models have three obvious peaks at the vehicle running speed of $60 \mathrm{~km} / \mathrm{h}$, the frequency of the nonlinear model is $0.48,8.00,13.11$ and $21.55 \mathrm{~Hz}$, the frequency of the linear model is $0.50,7.99,14.85$ and $22.11 \mathrm{~Hz}$. When the running speed is $80 \mathrm{~km} / \mathrm{h}$, the spectrograms of the nonlinear models have three obvious peaks which are 1.07, 3.92 and $11.93 \mathrm{~Hz}$, the spectrograms of the linear models have just one obvious peak which is $4.05 \mathrm{~Hz}$.

When the running speed is below $60 \mathrm{~km} / \mathrm{h}$, the peak frequency of linear model is almost the same as that of non-linear model. When the running is exceeding $60 \mathrm{~km} / \mathrm{h}$, the spectrograms of the linear model has deviated greatly from the nonlinear model. When the running speed is $80 \mathrm{~km} / \mathrm{h}$, the spectrograms of the linear models just have one obvious peak, which can't well reflect the low-frequency vibration of the pantograph-catenary system. Therefore, when considering the lateral excitation of the finger plate, only the nonlinear model can better reflect the low frequency vibration characteristics of the pantograph-catenary system.

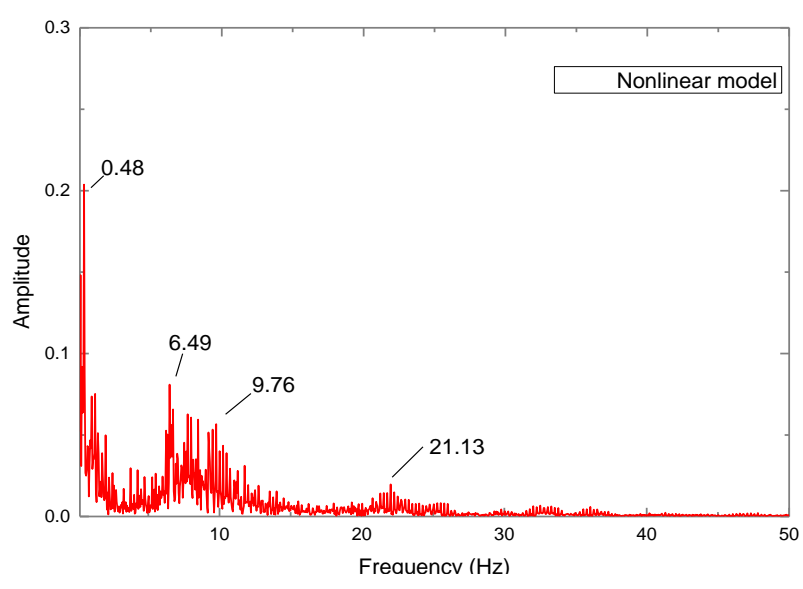

a

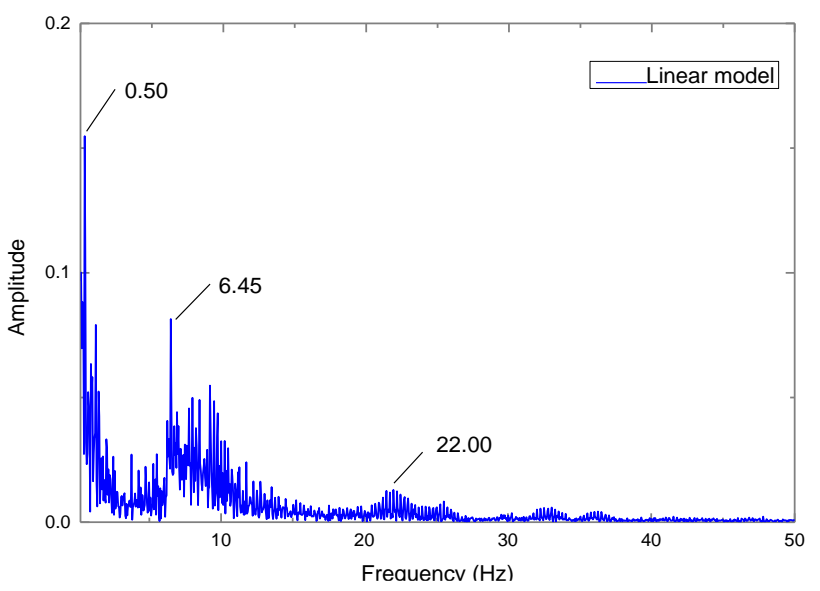

$\mathrm{b}$

Fig. 9 Frequency spectrum of contact force at the speed of $20 \mathrm{~km} / \mathrm{h}$ : a) nonlinear model; b) linear model 


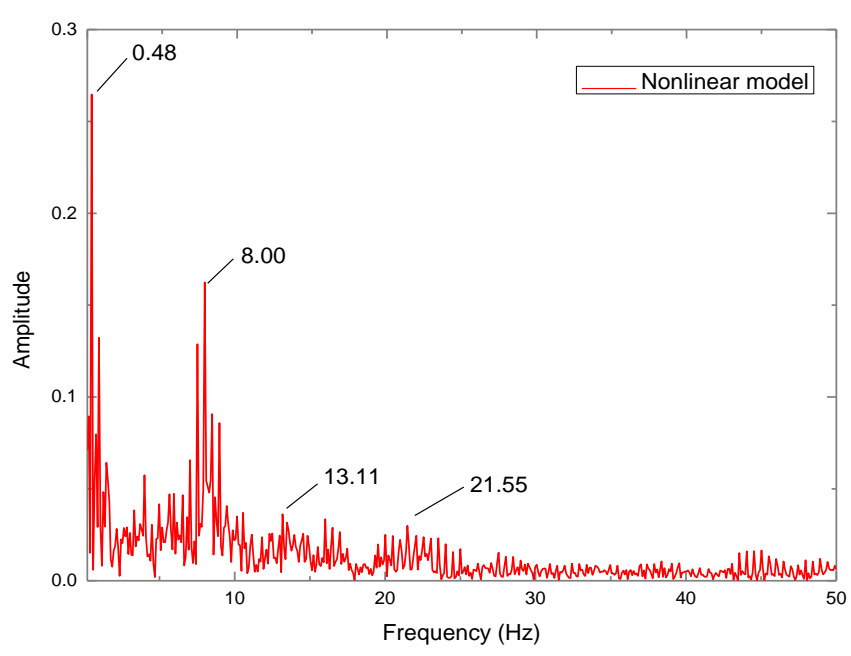

a

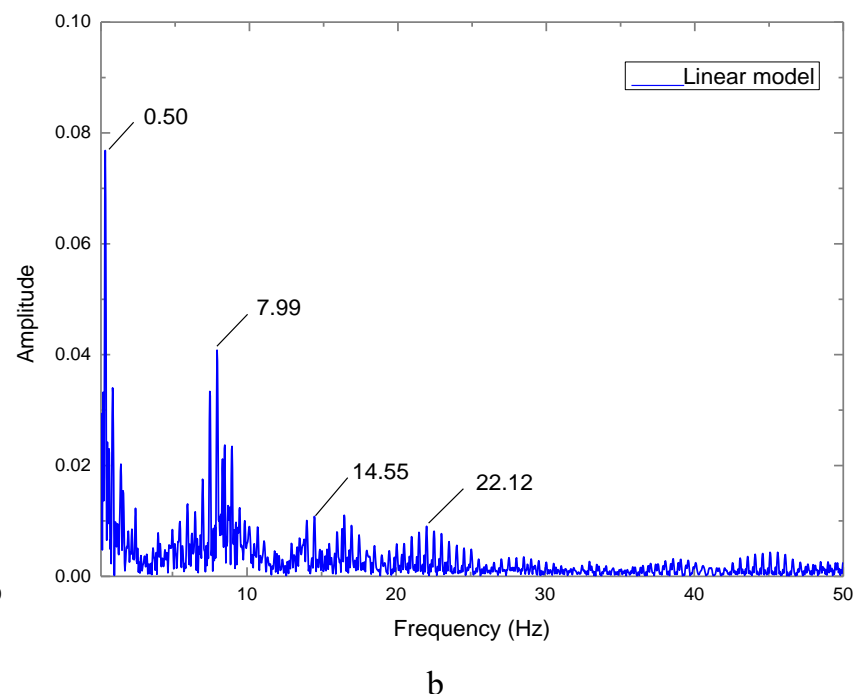

Fig. 10 Frequency spectrum of contact force at the speed of $40 \mathrm{~km} / \mathrm{h}$ : a) nonlinear model; b) linear model

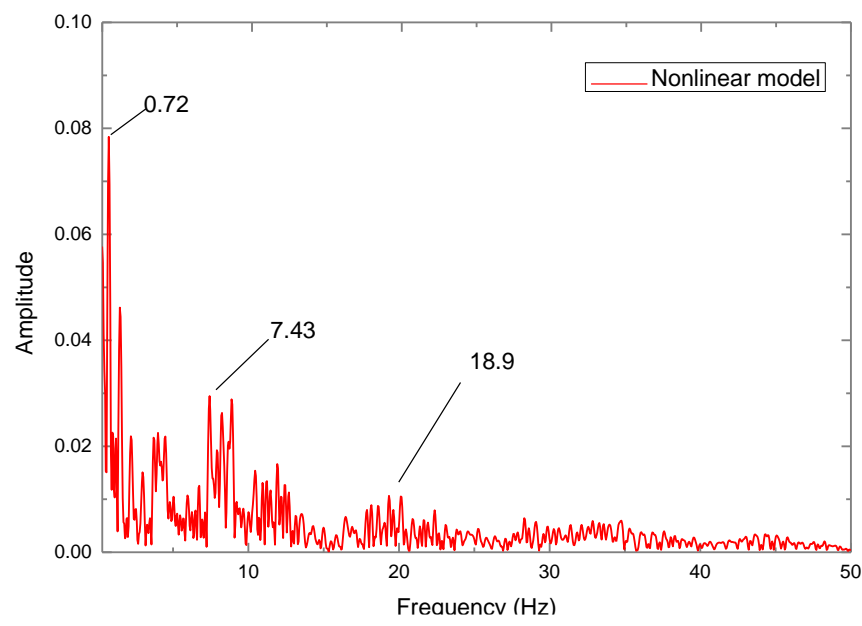

a

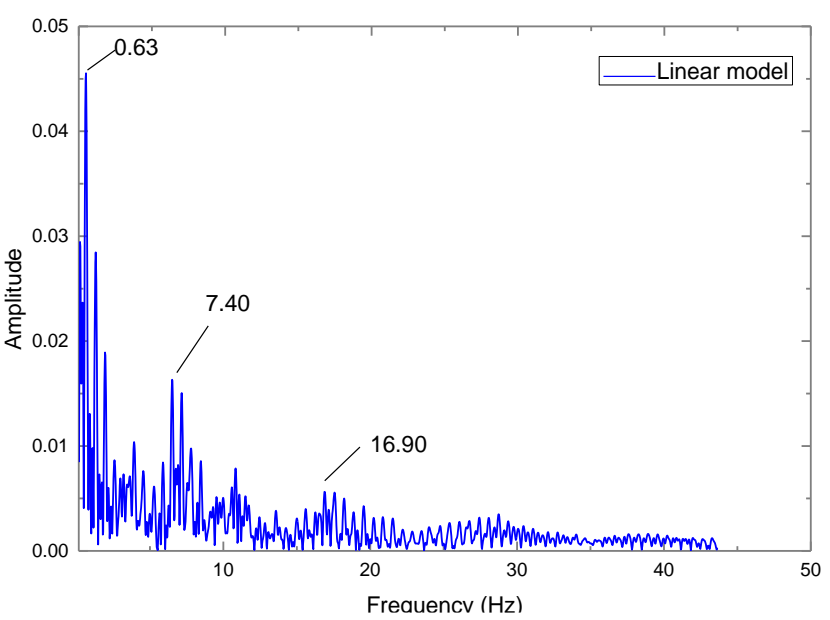

$\mathrm{b}$

Fig. 11 Frequency spectrum of contact force at the speed of $60 \mathrm{~km} / \mathrm{h}$ : a) nonlinear model; b) linear model

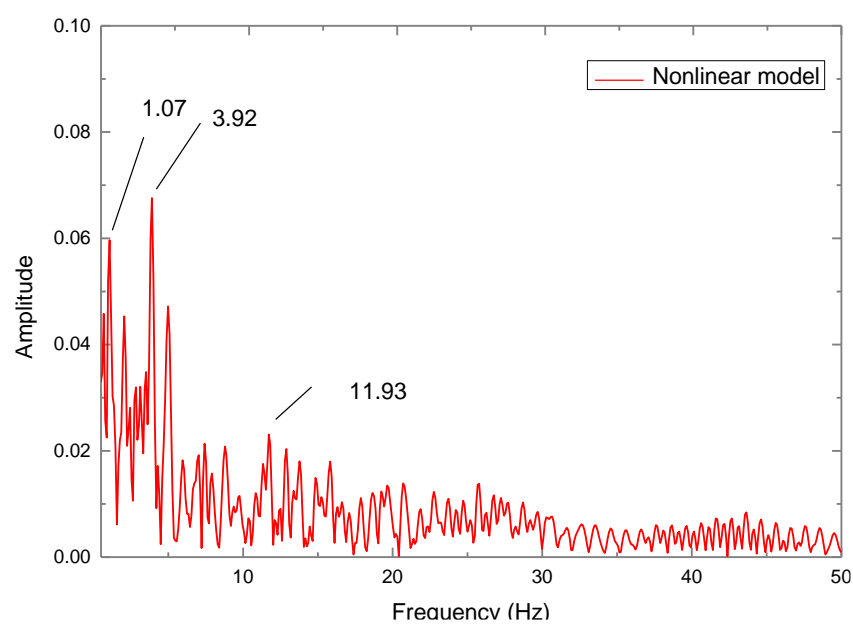

a

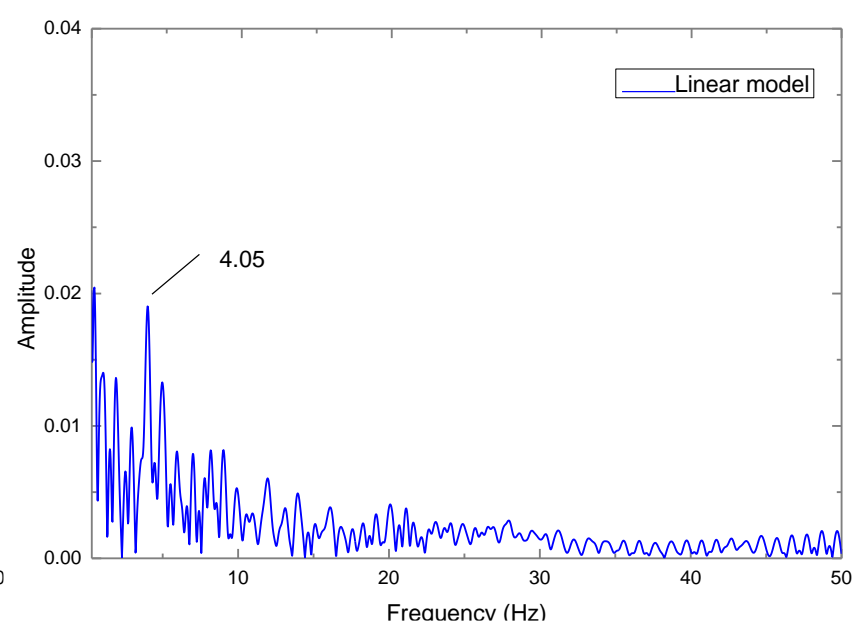

$\mathrm{b}$

Fig. 12 Frequency spectrum of contact force at the speed of $80 \mathrm{~km} / \mathrm{h}$ : a) nonlinear model; b) linear model

\subsection{Modal test of pantograph}

Using M + P modal test system to test the modal of pantograph is seen in Fig. 13 a and the test result is shown in the Fig. 13 b. The first main frequency of the pantograph is $20.5 \mathrm{~Hz}$, the second main frequency is $48.5 \mathrm{~Hz}$, and the third main frequency is $13.5 \mathrm{~Hz}$.

Analysis show that both models have the worst power collection quality when the running speed is $40 \mathrm{~km} / \mathrm{h}$. As can be seen from the test results of Fig. 13, b, the third main frequency of the pantograph is $13.5 \mathrm{~Hz}$. It can be seen from Fig. 10 that when the running speed is $40 \mathrm{~km} / \mathrm{h}$, the 
nonlinear model exhibits a vibration with a frequency of $14.55 \mathrm{~Hz}$, the linear model exhibits a vibration with a frequency of $13.11 \mathrm{~Hz}$, which is closed to the third main frequency of the pantograph. The pantograph system resonates with the excitation of the bow head, which leads to the decrease of power collection quality.

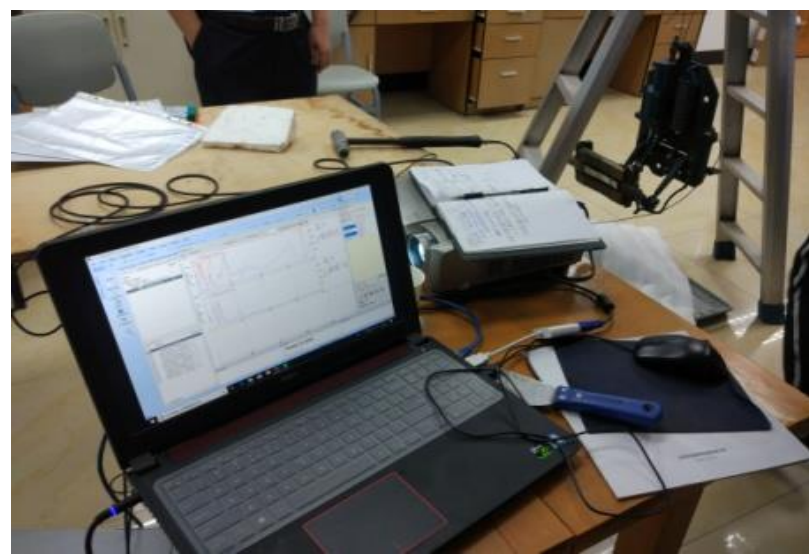

a

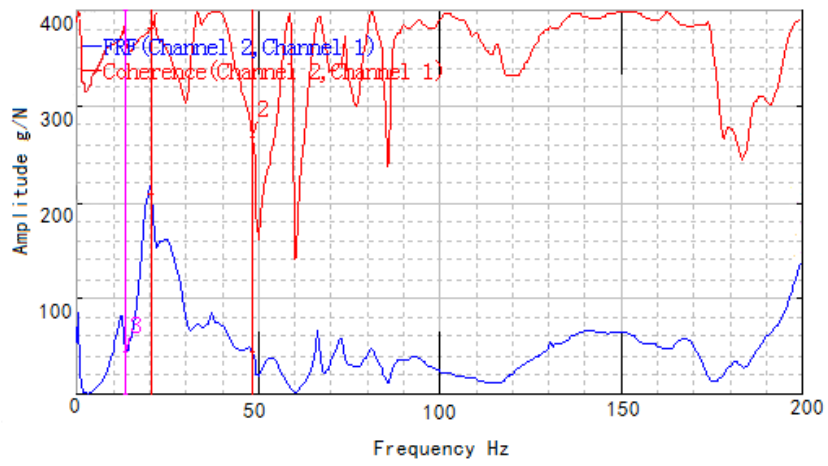

$\mathrm{b}$

Fig. 13 Modal test of pantograph: a) model test process of pantograph; b) modal test result of pantograph

\section{Conclusion}

The linear and nonlinear dynamic models of straddle monorail pantograph considering the lateral vibration of bogie are derived based on the Lagrange equation. On this basis, the lateral coupling dynamic model of pantograph and catenary is established.

In order to evaluate the applicability of the two models, this paper analyzed the contact force response of two models with different speeds.

1. When the speed is below $40 \mathrm{~km} / \mathrm{h}$, the contact forces of the two models are in good agreement, which reflects the transverse excitation of the finger plate. When the speed exceeds $40 \mathrm{~km} / \mathrm{h}$, only the nonlinear model can reflect the excitation caused by finger profiles, while the linear model can't clearly reflect the excitation.

2 . When the speed is below $60 \mathrm{~km} / \mathrm{h}$, both the nonlinear model and linear model can reflect the low-frequency vibration of pantograph-catenary system. When the speed exceeds $60 \mathrm{~km} / \mathrm{h}$, only the nonlinear model can reflect the low-frequency vibration of pantograph-catenary system.

3. When considering the lateral excitation of the finger plate, the pantograph system resonates with the excitation of the bow head, the pantograph-catenary system has the worst power collection quality when the running speed is $40 \mathrm{~km} / \mathrm{h}$.

Therefore, when considering the lateral vibration of the bogie, the nonlinear pantograph-catenary coupling dynamics model is more suitable for straddle-type monorail pantograph-catenary coupling research.

\section{Acknowledgement}

Fund Project: National Natural Science Foundation of China

Project Name: Research on the Mechanism and Control Method of Monorail Trains Running Tires' Shoulder Wear.

Project Number:51475062.

\section{References}

1. Masamichi, K.; Kenichi, Y.; Toshiharu, A.; Takayuki, T. 2004. Straddle-type Monorail Systems with Driverless Train Operation System, Hitachi Review 53(1).

2. Goda, K.; Nishigaito, T.; Hiraishi, M.; Iwasaki, K. 1999. Response analysis caused by track irregularity for a monorail (Japanese), Transactions of the Japan Society of Mechanical Engineers 65: 637.

3. Collina, Andrea; Bruni, Stefano. 2002. Numerical simulation of pantograph-overhead equipment interaction, Vehicle System Dynamics 38(4): 261-291. http://dx.doi.org/10.1076/vesd.38.4.261.8286.

4. Yang, S.; Zhigang, L.; Huajiang, O.; Hongrui, W.; \& Xiaobing, L. 2017. Sliding mode control with pd sliding surface for high-speed railway pantograph-catenary contact force under strong stochastic wind field, Shock and Vibration 2017: 1-16. http://dx.doi.org/10.1155/2017/4895321.

5. Mokrani, N.; Rachid, A. 2013. A robust control of contact force of pantograph-catenary for the high-speed train, 2013 European Control Conference (ECC), IEEE. http://dx.doi.org/0.23919/ECC.2013.6669668.

6. Kim, J. S. 2007. An experimental study of the dynamic characteristics of the catenary-pantograph interface in high speed trains, Journal of Mechanical Science and Technology 21(12): 2108-2116. http://dx.doi.org/10.1007/bf03177470.

7. Karakose, E.; Gencoglu, M. T. 2014. An investigation of pantograph parameter effects for pantograph-catenary systems. IEEE International Symposium on Innovations in Intelligent Systems \& Applications, IEEE. http://dx.doi.org/10.1109/INISTA.2014.6873641.

8. Duan, F. C.; Liu, Z. G.; Song, Y. 2016. Study on the current collection of high speed pantograph-catenary system considering static wind perturbation and friction coupling, 2016 35th Chinese Control Conference (CCC). IEEE. http://dx.doi.org/10.1109/ChiCC.2016.7554975.

9. Schaub, M.; Simeon, B. 2001. Pantograph-catenary dynamics: an analysis of models and simulation techniques, Mathematical and Computer Modelling of Dynamical Systems 7(2): 225-238. http://dx.doi.org/1076/mcmd.7.2.225.3644.

10. Massat, J. P.; Laurent, C.; Bianchi, J. P.; Balmès, Etienne. 2014. Pantograph catenary dynamic optimization based on advanced multibody and finite element cosimulation tools, Vehicle System Dynamics 52(sup1): 338-354. 
http://dx.doi.org/10.1080/00423114.2014.898780.

11. Bocciolone, M.; Resta, F.; Rocchi, D.; Tosi, A.; Collina, A. 2006. Pantograph aerodynamic effects on the pantograph-catenary interaction, Vehicle System Dynamics 44(sup1): 560-570. http://dx.doi.org/10.1080/00423110600875484.

12. Garg, R.; Mahajan, P.; Kumar, P.; \& Gupta, V. 2014. Electrical prototype model of pantograph-catenary system, Transportation Electrification Asia-pacific, IEEE. http://dx.doi.org/10.1109/ITEC-AP.2014.6941179.

13. Tong-Jin lark.; Byung-in Kim.; Young-Yong Wang. 2002. A Catenary System Analysis for Studying the Dynamic Characteristics of a high speed rail pantograph, KSME International Journal 16(4):436-447. http://dx.doi.org/10.1007/BF03185073.

14. Alberto, A.; Jesús Benet.; Arias, E.; Cebrian, D.; Tomás Rojo, \& Cuartero, F. 2008. A high performance tool for the simulation of the dynamic pantograph-catenary interaction, Mathematics and Computers in Simulation 79(3): 652-667. http://dx.doi.org/10.1016/j.matcom.2008.04.016.

15. Pombo, J.; Ambrósio, J. 2013. Environmental and track perturbations on multiple pantograph interaction with catenaries in high-speed trains, Computers \& Structures 124:88-101. http://dx.doi.org/10.1016/j.compstruc.2013.01.015.

16. Massat, J. P.; Laurent, C.; Bianchi, J. P.; \& Balmès, Etienne. 2014. Pantograph catenary dynamic optimisation based on advanced multibody and finite element cosimulation tools, Vehicle System Dynamics 52(sup1): 338-354. http://dx.doi.org/10.1080/00423114.2014.898780.

17. Rauter, F. G.; Pombo, J. Multibody modeling of pantographs for catenary-pantograph interaction [C], III European Conference on Computational Mechanics 2006: 334-334.

18. Ambrosio, J.; Rauter, F. 2011. A Flexible Multibody Pantograph Model for The Analysis of the CatenaryPantograph Contact. Multibody Dynamics. Springer127. http://dx.doi.org/10.1016/j.compstruc.2013.01.015.

19. Zhen Yang; Zixue Du; Cheng Chen; Xiao xia Wen; Zhouzhou Xu. 2017 . Research on the influence of straddle-type monorail's pantograph head parameter on power collection quality, Urban Rail Transit 3 (3) :149157.

http://dx.doi.org/10.1007/s40864-017-0066-0.

ZX. Du, Z.Yang, ZZ. Xu, JC. Zhou, ZW. Hou

\section{THE STUDY ON NONLINEAR MODEL OF PANTOGRAPH-CATENARY COUPLING SYSTEM FOR STRADDLE-TYPE MONORAIL}

S u m m a r y

Based on the Lagrange equation, the linear and nonlinear dynamic models of straddle monorail pantograph considering the lateral vibration of bogie are derived. On the basis, the lateral coupling dynamic model of pantograph-catenary is established. Newmark method is used to solve the pantograph-catenary coupling dynamic model. In order to evaluate the applicability of the two models, this paper analyzed the contact force response of two model with different speeds. The research show that when the speed is below $40 \mathrm{~km} / \mathrm{h}$, the contact forces of nonlinear model and linear model can reflect the lateral excitation of the finger plate. When the speed exceeds $40 \mathrm{~km} / \mathrm{h}$, only the nonlinear model can reflect the lateral excitation caused by finger plate. The nonlinear pantograph-catenary coupling dynamics model is more suitable to the straddle-type monorail pantograph-catenary coupling system research.

Keywords: straddle-type monorail, nonlinear models, linear models, pantograph, lateral excitation.

Received September 25, 2019 Accepted June 02, 2020 